\title{
INVESTIGATION OF AUDIENCE VIEWING ANGLE IN THE COLLECTION OF PROPOSED SECTION OF THE 3RD TEHRAN MURAL PAINTING BIENNIAL
}

\author{
Yousef Rajabi \\ MA Students, Field of Visual Communications, Faculty of Engineering, West Tehran Branch, Islamic \\ Azad University, Iran \\ Yousef_r2ka@yahoo.com \\ Dr. Seyed Nezamoddin Emamifar \\ Assistant Professor, Faculty of Arts, Shahed University, Iran \\ N_emamifar@yahoo.com
}

\begin{abstract}
Mural painting as one of the most influential sectors of public art, in the level of today's cities with different objectives addressed in the stylized visual disturbances in urban areas which can have a significant effect on activation and dynamics of these spaces. Mural painting in each of the three fields (vision, reading, distinct) interact differently with environment and audience and led to the emergence of the identity of its concept suited to each, as among the features of a successful mural, relation to the environment and the audience, the need for careful examination of the field of view and reading is very important. Research method was based on a descriptive and analytical nature and data collection method is used in combination (library, field and internet). The population of 16 collection of proposed section of the 3RD Tehran Mural Painting Biennial. Sampling method is in the form of non-random (optional) and the number of sample 1 work and data analysis information method is also qualitatively. The purpose of this paper is to investigate the audience viewing angle in the collection of proposed section of the 3RD Tehran Mural Painting Biennial.
\end{abstract}

Keywords: witnesses of city, mural painting, mural, Shahid, audience viewing angle

\section{INTRODUCTION}

Urban mural painting was an integral part of the urban identity and is considered to be one of the most important factors in creating a good atmosphere in the urban landscape in recent decades. The urban growing trend leads to the creation of urban spaces and urban landscape and hence according to urban aesthetics and create a favorable environment will play an important role in mind and thought and lifestyle of citizens. Mural painting refers to any image that is created with a specific purpose and informed on the wall. But urban mural painting has minor and specific concept. Studied mural painting, deals such as mural painting with subject of holy defense and the place of martyrdom and examines the audience viewing angle to the proposed works.

\section{About Biennial}

The 3RD National Mural Painting Biennial with a focus on subjects of Quran, chants and Islamic traditions, events in the life of Imam Khomeini and the Supreme Leader and also the memory of veterans including scenes of heroism of the martyrs and their comrades, this allowed artists to once again serve this country with the memory of Imam and martyrs from the filter of their mind, host high values of the Islamic Revolution. In the cultural context of our country need to be attractive and understandable for the public urban mural painting and Islamic and Iranian values to be reminded. This requires the establishment of a large and influential festivals. Specialized festivals where talented artists have exhibited their innovation and ideas in the form of a great artistic event. 


\section{Attention to the martyrs and its relationship with urban mural painting}

"The art of mural painting in different civilizations throughout history, ethnic origin, culture and values of the nation image of the chest walls. These works were created under the influence of events of different periods and with the benefit of icons and symbols of the culture of each region." (Youzbashi and Ansari, 2015: 382) Mural painting had the opportunity in targeted human possession to the consolidation of its ideals, constantly throughout the history of life and the environment, to employ this art such as mass media and thereby remind their heroes and myths of their society. (Kafshchian Moghadam, 2015: 135) When drawing of martyrs drawn on the wall, in such a way interact with the environment, which lead the viewer to the concepts of value. Perhaps the most important goals of mural painting in cities addition to its media aspect, undoubtedly is beauty of work and environment. In this regard, it is necessary to the internal structure of work is the benefit of aesthetic features and beauty effects in the interaction with the environment. In addition, the role of the audience in the meantime should not be forgotten. Although beauty is a relative thing, but as public works relies on the collective memories (ethnic, local, national, religious, etc.), mural painting works of martyrs also is subscription-based conceptual and aesthetic of the collective memories that effect must be attended to implement them. Society with the discovery of new patterns in the form of national heroes, the desire to respect and honor them and to have their mythic archetypes in new icon in their living environment. (Kafshchian Moghadam, 2015: 136)

\section{The purpose of the mural painting of Martyrs in urban areas}

Attending to the status of martyr and honoring it's no secret, especially because we live in an Islamic society. With the passage of time and the victory of the Islamic Revolution and subsequent to the end of the war, revolutionary mural paintings with various themes and concepts revolving around the martyr was considered more and because people and diversity executive formats mural painting in order to be able to have more effect than other visual arts. Islamic Revolution was still new that in September 1980 the Iraqi army invaded Iranian territory. War overshadowed all spheres of political, cultural and social areas of life in Iran and the new system. The mural, which was also in the midst of the arts in the service of war. (Salari, 2011:331) Values defined in the new system and the necessities of war propaganda causing visual artists explain their situation towards them. The presence of academic artists in mural painting of this period resulted in a variety of visual expression of this work. Mural painting during the war, with all its shortcomings were the values that fit in the right direction can founded art commensurate with the Islamic Republic. (Kafshchian Moghadam and Royan, 2008: 107) These murals at the beginning of the graffiti and the image of the religious and intellectual figures of the Islamic Revolution and sometimes with simple graphics but effective such as the rejection of bloody hands to indicate innocence, is shown. (Ali Mohammadi Ardakani, 2008: 474) In fact, people used whatever means during the Islamic Revolution in order to explain this great movement and mural works were created at the beginning of the revolution by the people and folk artists spontaneously and based on community needs. Popular artists who are located in the heart of the revolution sooner than academic artists in this initiative, they were able to hear the message of the revolution with all their revolutionary enthusiasm. Another point that has been emphasized in the mural painting, is wide communication and the public as a public media and its relationship with the audience. In this regard, it should be noted visual impact and thematic work on the audience. These effects can be cultural, social, political, religious and even mental. The mural painting is a multidimensional art which makes it more difficult aspects of the review. Undoubtedly honoring the martyr status, is not secret to nobody and all government and public organizations seek to somehow share in honoring the memory of the martyrs of the holy defense. So this mural painting for this purpose, can have more effects than other visual arts. (Kafshchian Moghadam, 2006: 20) 


\section{Audience viewing angle in the works studied}

Growth in Tehran was very large, this has led to a complete revision of urban space is needed; including attention to compliance with the contemporary architectural space and contact visual culture, the exact calculation of the breadth of vision of urban space to read, modify and related relaxation spaces in the wall series, which is ultimately aimed to beautify the urban space, stylized visual space environment and pleasant environment impact on the audience. Doctor Kafshchian Moghadam in No. 22 of Negareh Scientific Research Journal refers to the field (vision, reading, distinct) and is described as:

Field of vision: separating limit between the audience and the wall (the whole works) is seen walls and murals.

Field of readings: separating limit between the audience and the wall (the whole works) that wall effect is perceived at a glance.

Field of distinct: separating limit between the audience and the wall (the whole works) the impact of texture and it tangible recognition technology.

Mural painting in each of the three fields (vision, reading, distinct) a different way to interact with the environment and audience and led to the emergence of the identity of its concept suited to each, as the characteristics of a successful mural painting, associated with the environment and the audience, the need for careful examination of the field of vision and reading is very important until the effects of drawing on the walls can make understandable visual identity and significance in the position of fixed or movable. Given that could make a big difference in the type of presentation of target plan and visual qualities and expressive work. The importance of this issue, the coordination and communication with the audience and environment effects, such that the audience is not passive role in front of the work, but by the quantity and quality of time and space and to recognize changes its position relative to the work involved in the sense of it and can be seen every time the combined effect of moving towards fresh and new.

While mural painting should be designed and implemented in such a way that they invite the audience to see, if the audience does not have to visually see disharmony. For example, the dimensions of the mural painting can be distinguished them from the poster species. This aspect helps the audience see themselves in a new environment, in addition to being attractive and avoid monotony, mural painting designs will be added to the urban space and even challenge the audience for a few seconds. Gradually, with changes in the design of murals, tastes of municipal people change and of course, taste and even problems of strengthening friendly. The effect of mural painting in the urban space, especially on the subject of revolution and martyrdom has a special place in people's minds and can be a profound and lasting cultural movement.

\section{The collection of proposed section of the 3RD Tehran Mural Painting Biennial}

Works in the competition "witnesses of city" from between 1800 works from 600 artists, for 500 Wall detected by 22 districts of Tehran municipality, was selected by a jury on 29 January 2015 and 159 were due to compete. In the article 16 of the proposed work, 3 works are due importance to the audience viewing angle, ie $30 \%$ of the works met the audience viewing angle and 70 percent did not meet. (Table 1) and a sample has been analyzed.

Table 1: The collection of proposed section of the 3RD Tehran Mural Painting Biennial

\begin{tabular}{|c|c|c|c|c|c|c|c}
\hline No & Author & Work & $\begin{array}{c}\text { viewi } \\
\text { ng } \\
\text { angle }\end{array}$ & No & Author & Work & $\begin{array}{c}\text { viewi } \\
\text { ng } \\
\text { angle }\end{array}$ \\
\hline
\end{tabular}


The Turkish Online Journal of Design, Art and Communication - TOJDAC August 2016 Special Edition

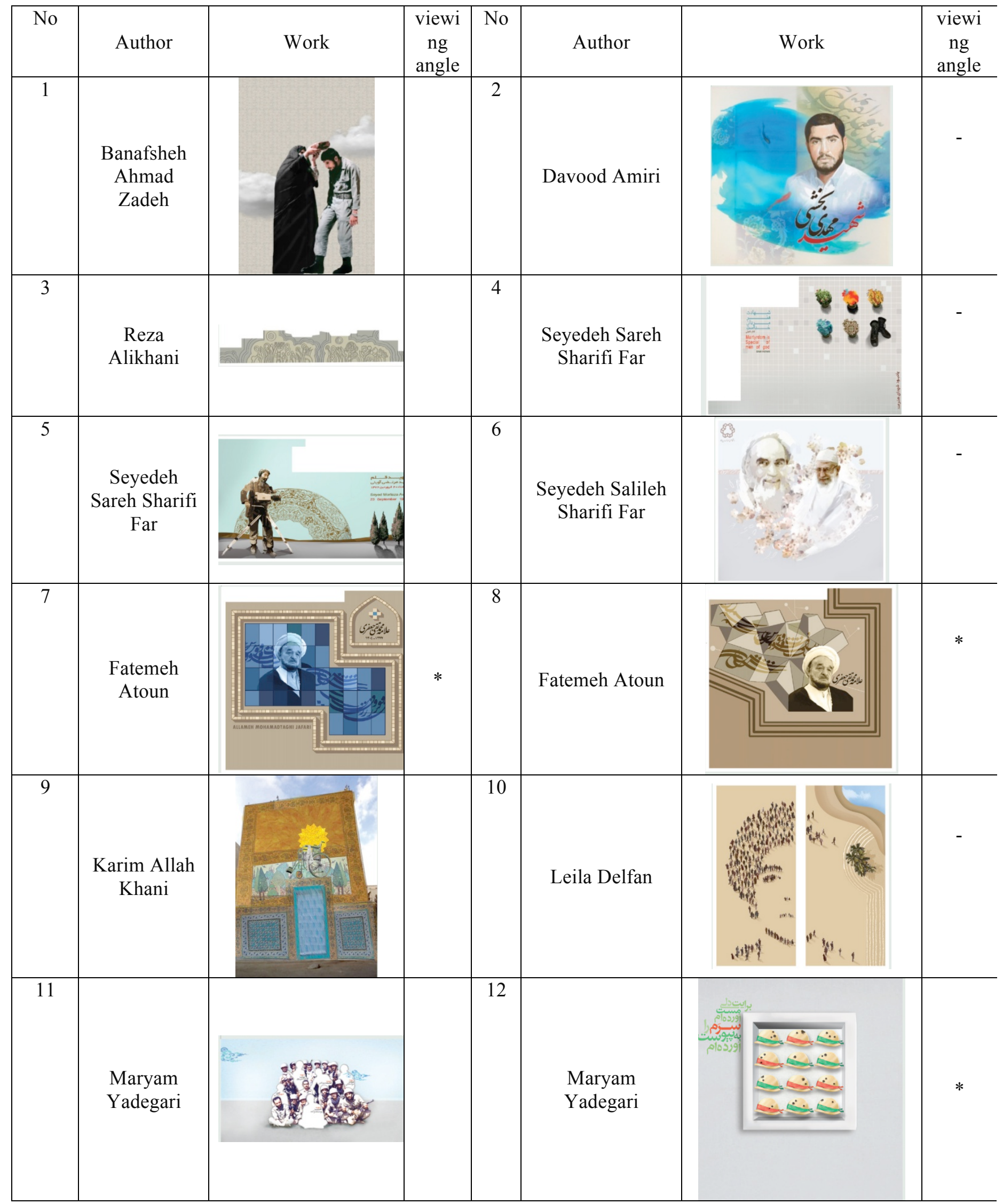




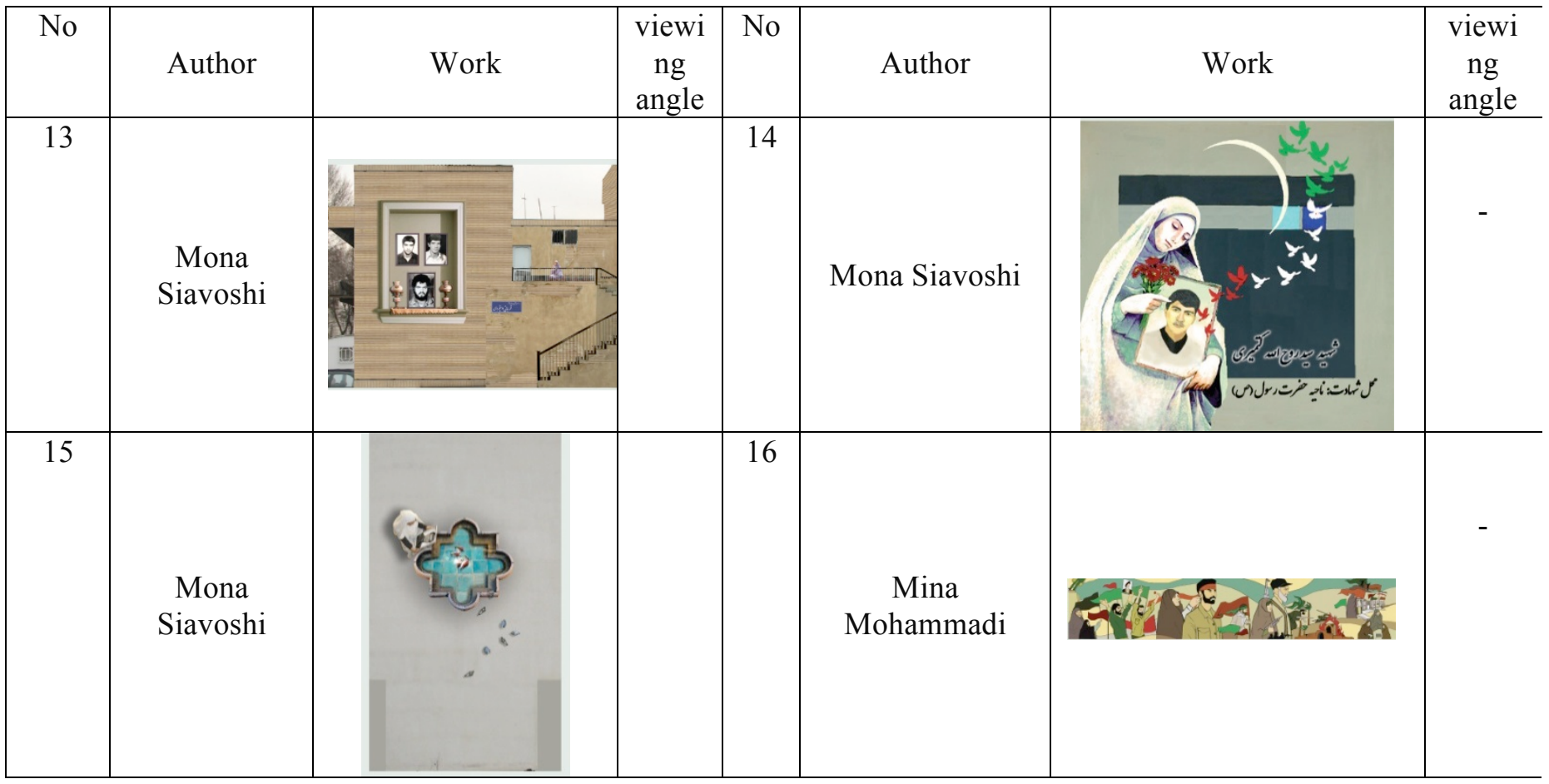

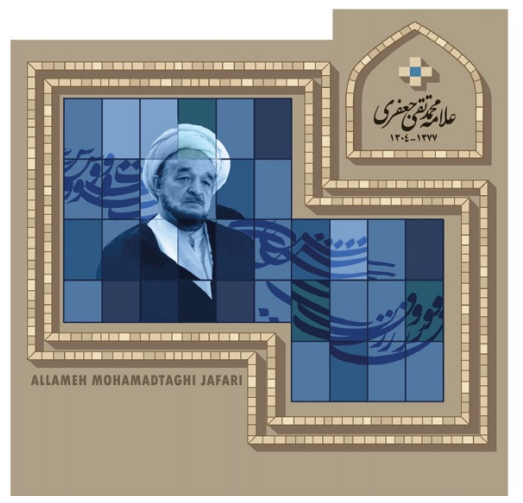

Figure 1. Proposal. Tehran. Kashani Street, Artist: Fatemeh Atoun

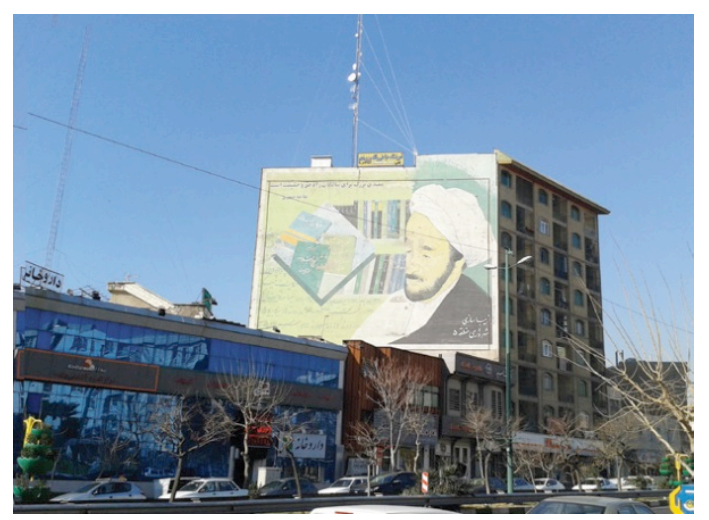

Figure 2. The present situation of selected wall. Tehran. Kashani Street 


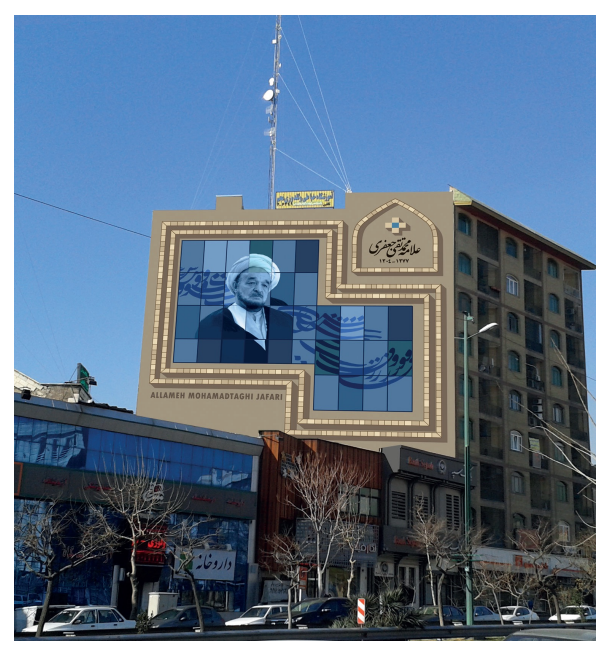

Figure 1. Locating the proposal. The 3RD Tehran Mural Painting Biennial. Tehran. Kashani Street, Artist: Fatemeh Atoun

The proposed sample for analysis

Table 2: samples of analysis. Proposed Section of the 3RD National Tehran Mural Painting Biennial

\begin{tabular}{|c|c|c|c|c|c|c|c|c|c|}
\hline \multicolumn{10}{|c|}{ Forming visual elements: point, line, area, volume, texture } \\
\hline 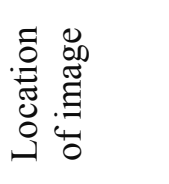 & 营莺 & $\begin{array}{l}\frac{\ddot{U}}{0} \\
\frac{0}{0} \\
\tilde{D}\end{array}$ & $\frac{\overline{0}}{0}$ & 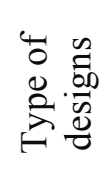 & 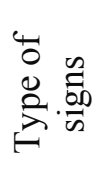 & 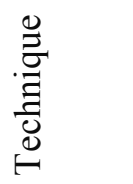 & 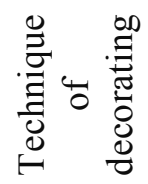 & 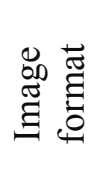 & 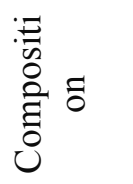 \\
\hline $\begin{array}{c}\text { Tehran, } \\
\text { Kashani } \\
\text { Street }\end{array}$ & $\begin{array}{l}\text { Fatem } \\
\text { eh } \\
\text { Atoun }\end{array}$ & $\begin{array}{c}\text { Allama } \\
\text { Moha } \\
\text { mmad } \\
\text { Taqi } \\
\text { Jafari }\end{array}$ & $\begin{array}{l}\text { Brown } \\
\text { and } \\
\text { blue } \\
\text { tone }\end{array}$ & $\begin{array}{l}\text { Geo } \\
\text { metri } \\
\mathrm{c}\end{array}$ & $\begin{array}{c}\text { Symb } \\
\text { olic }\end{array}$ & Acrylic & $\begin{array}{c}\text { Tiling, } \\
\text { brickwo } \\
\text { rk, black } \\
\text { homewo } \\
\text { rk }\end{array}$ & $\begin{array}{c}\text { Squar } \\
\mathrm{e}\end{array}$ & $\begin{array}{l}\text { Decentr } \\
\text { alized }\end{array}$ \\
\hline
\end{tabular}

Picture of Allama is placed on the left side of wall. And the two square box that the artist inside the box and has seven colors for tile (clay tiles that originated from imitation); in the small square box, black text underfloor heating is started and directed towards the larger square box that is placed picture of Allama on it. This Nastaliq broken lines is not readable and as tissue box placed in the background. But is likely poem by Rumi because Allama is philosopher and Rumi gourmet and also contains a symbol of Allama being Iranian. Flat colors and blue tone has used in tiling and round square boxes, composed of an array of smaller squares that evokes the art of brickwork to the audience; has brown tone and with the use of flat color, give it dimension and depth. In the small square box, picture of the altar is seen. That Allama name is written inside it and Allama name in English is placed at the bottom of a large square box. (Picture 1) Due to the flat and angular colors are associated with the volume, the audience viewing angle in the plan were met. (Picture 2) Structural tissue of these motifs are similar to motifs of Islamic religious places like mosques (the designs in tile, stucco, etc. have been imported) (Table 2) (Youzbashi, Emamifar, 2015: 1945)

\section{CONCLUSION}

Martyrdom in the Islamic Republic is a genuine process; Stream where human beings passes and die for their belief, of opinion and his/her own country. Among this, martyr's face is the closest document Image to his/her act. Factors that old painters in the depiction of prophets and Imams used it. But with studies and the results obtained in this paper studied the works, we realize that this Biennial artists 
have tried to create different effects than before and mural painting history in Iran. In total, they have been valued for its urban audience and away from repetitive elements and with respect to the audience viewing angle with respect to the theoretical foundations of visual art works, as well as clever use of imagery have created the image of martyrs. Due to the fact that the walls are suitable for mural painting in the drawing and implementation of highways and city streets, the wall needs to be examined in terms of audience, it is not blocking elements such as trees, signs and even buildings and not distort the readings murals. Because most of them were long ago a great place to create murals but with the passage of time and the growth of seedlings that were very small at that time, many murals have lost their readings and hiding behind a clump of trees, and even non-normative constructions. Therefore, attending to this issue in this part of environmental art is essential.

\section{REFERENCES}

1. Kafshchian Moghadam, Asghar. (2008), Negareh Analysis - Research Journal, Seventh number, pp. 18-20.

2. Kafshchian Moghadam, Asghar and Roya, Samira. (2008), "Investigation of Tehran Contemporary mural painting," Journal of Fine Arts, (33): p. 107.

3. Kafshchian Moghadam, Asghar and Kafshchian Moghadam, Reyhaneh. (2015), "Why martyrs mural painting ...", Book of articles collection of the 3RD Tehran Mural Painting Biennial, pp. 134- 15.

4. Kafshchian Moghadam, Asghar., (2006), "Burnt buds: mural painting movement of revolution ", Journal of Oriental Imagination, 3: pp. 18-27.

5. Salari, Hamid (2014), "The Pathology of mural painting of martyrs and holy defense", Articles collection of the 3RD Tehran Mural Painting Biennial, pp. 329-342.

6. Alimohammadi Ardakani, Javad. (2008), "Environmental Graphic apparent conflict between the values", Journal of Oriental Imagination, (4), pp. 470-475.

7. Youzbashi, Atieh and Ansari, Hamideh. (2015), "Symbol of wall painting of witnesses of city, Islamic Revolution and holy defense (the culture of sacrifice and martyrdom)," Book of articles collection of the 3RD Tehran Mural Painting Biennial, pp. 381- 396.

8. Youzbashi. Atieh and Emamifar. Seyed Nezamoddin, (2015), "Semiology Study of Shrine Geometric patterns of Damavand City of Tehran Province1" INTERNATIONAL JOURNAL OF HUMANITIES AND CULTURAL STUDIES ISSN 2356-5926, 1942- 1960. 